\section{(C) OPEN ACCESS}

\title{
The incidence and prevalence of systemic lupus erythematosus in the UK, 1999-2012
}

\author{
Frances Rees, ${ }^{1,2}$ Michael Doherty, ${ }^{1}$ Matthew Grainge, ${ }^{3}$ Graham Davenport, ${ }^{4}$ \\ Peter Lanyon, ${ }^{1,2}$ Weiya Zhang $^{1}$
}

\begin{abstract}
Handling editor Tore K Kvien
- Additional material is published online only. To view please visit the journal online (http://dx.doi.org/10.1136/ annrheumdis-2014-206334)

'Division of Rheumatology, Orthopaedics and Dermatology, University of Nottingham, Nottingham, UK

${ }^{2}$ Rheumatology Department, Nottingham University Hospitals NHS Trust,

Nottingham, UK

${ }^{3}$ Division of Epidemiology and Public Health, University of Nottingham, Nottingham, UK ${ }^{4}$ Arthritis Research UK Primary Care Centre, Keele University, Keele, UK
\end{abstract}

\section{Correspondence to} Dr Frances Rees, Academic Rheumatology, The University of Nottingham, Room A27, Clinical Sciences Building, City Hospital, Nottingham NG5 1PB, UK:

frees@doctors.org.uk

Received 22 July 2014 Revised 2 September 2014 Accepted 13 September 2014 Published Online First 29 September 2014

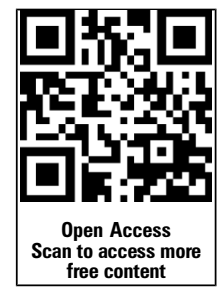

\section{CrossMark}

To cite: Rees F, Doherty M, Grainge $\mathrm{M}$, et al. Ann Rheum Dis 2016;75:136141.

\section{ABSTRACT}

Objectives To estimate the incidence and prevalence of systemic lupus erythematosus (SLE) in the UK over the period 1999-2012.

Methods A retrospective cohort study using the Clinical Practice Research Datalink (CPRD). The incidence was calculated per 100000 person-years and the prevalence was calculated per 100000 people for the period 1999-2012 and stratified by year, age group, gender, region and ethnicity. Three definitions of SLE were explored: (1) systemic lupus, (2) a fully comprehensive definition of lupus including cutaneous only lupus and (3) requiring supporting evidence of SLE in the medical record.

Results Using our primary definition of SLE, the incidence during the study period was $4.91 / 100000$ person-years $(95 \% \mathrm{Cl} 4.73$ to 5.09$)$, with an annual $1.8 \%$ decline $(p<0.001)$. In contrast, the prevalence increased from 64.99/100 000 in $1999(95 \% \mathrm{Cl} 62.04$ to 67.93$)(0.065 \%)$ to $97.04 / 100000$ in $2012(95 \% \mathrm{Cl}$ 94.18 to 99.90$)(0.097 \%)$. SLE was six times more common in women. The peak age of incidence was 50 59 years. There was regional variation in both incidence and prevalence. People of Black Caribbean ethnicity had the highest incidence and prevalence. Alternative definitions of SLE increased (definition 2) or decreased (definition 3) estimates of incidence and prevalence, but similar trends were found.

Conclusions The incidence of SLE has been declining but the prevalence has been increasing in the UK in recent years. Age, gender, region and ethnicity are risk factors for SLE. This is the first study to report ethnic differences on the incidence and prevalence of SLE using the CPRD.

\section{INTRODUCTION}

Systemic lupus erythematosus (SLE) is a rare, chronic autoimmune disease which can vary from mild to potentially life-threatening. The majority of previous studies that estimated the incidence and prevalence of SLE in the UK were single-centre hospital-based studies. ${ }^{1-5}$ These estimated the incidence to be $3.8-4.0 / 100000$ person-years and the prevalence 6.5-27.7/100 000 people. Most only included patients who fulfilled four of the 1982 American College of Rheumatology (ACR) classification criteria, ${ }^{6}$ thereby excluding mild cases or those who did not fulfil four criteria despite severe disease, for example, lupus nephritis. More recently, the Clinical Practice Research Datalink (CPRD), formerly known as the General Practice Research Database, has been used for this purpose. Using the
CPRD, the incidence for SLE during the 1990s was estimated to be between 3.0 (95\% CI 2.7 to 3.3) and 4.7 (95\% CI 4.5 to 4.9$) / 100000$ person-years and the prevalence between 25.0 (95\% CI 23.4 to 26.7) and 40.7 (95\% CI 37.6 to 43.8)/100 000 persons. $^{7-9}$ The incidence estimates differed due to variation in defining the study population and incident cases. ${ }^{10}$ Both excluded certain subtypes of cutaneous lupus and were more likely to exclude mild cases. The prevalence estimates increased with time during the 1990s. This was suggested to be due to recording a relapsing-remitting disease within a longitudinal database, rather than an actual increase in prevalence. However, one of the incidence studies found a small but non-significant increase in the incidence of SLE in females over time and studies in other European countries have found an increased temporal trend. ${ }^{11-13}$

The aim of this study was to examine the incidence and prevalence for SLE in the UK for the most recent decade, including temporal trends, variation with age, gender, region and ethnicity. To better understand the nature of SLE, three different definitions were examined: (1) systemic lupus, (2) a fully comprehensive definition of lupus including cutaneous only lupus and (3) any lupus case with supporting evidence of SLE in the medical record.

\section{METHOD}

\section{Study design and study population}

A retrospective cohort study was conducted using the CPRD, a longitudinal database of UK general practice records incepted in 1987 and deemed to be representative of the UK population. ${ }^{14}$ As of January 2013, there were 660 practices contributing anonymised records for approximately 12 million people in all four countries of the UK. Practices record patient demographics, consultations, hospitalisations, specialist referrals, prescriptions, test results, immunisations and diagnoses using Vision Practice Management Software. Clinical information is entered using Read codes, a standard clinical terminology system used in general practice in the UK. Prescriptions are recorded using Multilex (or British National Formulary (BNF)) codes. Researchers access data through the CPRD website or annual flat files. The quality of the data is regulated by the Medicines and Healthcare Products Regulatory Authority (MHRA).

Participants were males and females contributing data during the period 1 January 1999 to 31 December 2012. Participants were eligible from the date their practice was deemed to be contributing 
'up-to-standard' (UTS) data and their individual record was of 'acceptable' research quality as verified by the CPRD. When calculating incidence at least 12 months registration prior to study entry was required. A minimum period of 1 year following registration has been suggested to minimise the risk of prevalent cases being coded as incident cases for chronic diseases ${ }^{15}$ and was used in a previous SLE study. ${ }^{8} \mathrm{~A}$ minimum period of 3 years postregistration was analysed for comparison.

For consenting English practices, ethnic group data were available through linkage to Hospital Episode Statistics (HES). HES records patient demographics, primary diagnosis, procedures, intensive care stays and maternity data for hospital admissions since 1997 using International Classification of Diseases (ICD)-10 codes. Linked data were only used to obtain ethnic group as this was not available on the January 2013 release of the CPRD dataset.

Independent Scientific Advisory Committee for MHRA Database Research approval was obtained for this study on 4 June 2013 (Protocol 13_092).

\section{Case definition}

Read codes for SLE were selected from the CPRD medical dictionary browser using the search terms 'lupus' and 'SLE' (see online supplementary table S1). Three definitions were used. The first definition 'systemic lupus' included all codes that represented SLE or a subtype of SLE excluding cutaneous only lupus. Codes relating to a diagnostic test, a scoring system, tuberculosis, lupus pernio, drug-induced lupus or neonatal lupus were excluded. Selected codes were verified by 6 co-investigators (3 rheumatologists (FR, MD, PL), 1 epidemiologist (WZ), 1 statistician and CPRD expert (MG) and 1 general practitioner (GP) (GD)). The second definition was fully comprehensive including cases with cutaneous only subtypes. The third definition required a record of either a positive immunological blood test result (ANA, anti-dsDNA, ENA or anti-Ro), a prescription for a drug used in SLE (hydroxychloroquine, azathioprine, methotrexate, mycophenolate mofetil, ciclosporin, cyclophosphamide, rituximab, prednisolone) or a referral to a rheumatologist from cases identified in definition 2.

The date of first code was taken as the date of diagnosis. Individuals with a code for SLE but without a diagnosis date were excluded $(n=49)$.

External validation of SLE diagnosis was not conducted because: (1) there was no additional funding or time available for this; (2) GPs would be unlikely to give a patient a Read code for SLE unless it had been confirmed by a hospital specialist (personal communication, GD); and (3) validation of other autoimmune diseases on the CPRD has shown positive predictive values of $>90 \% .^{1617}$

\section{Outcome measures and analysis}

Incidence was calculated by dividing the number of new cases of SLE by the number of person-years from eligible participants during the study period. For each year of follow-up, the entry date was the latest of 1 January, UTS date or the date of registration plus 365 days. The exit date was the earliest date of incident SLE diagnosis, death, transfer-out of a participating CPRD practice, date of last data collection from a practice or 31 December of the specified year.

Prevalent cases were all live cases of SLE on the database meeting the eligibility criteria on the 1 July of each year. Point prevalence was calculated by dividing the number of prevalent cases by the number of people on the CPRD who had UTS and 'acceptable' data on the 1 July of each year.
Incidence and prevalence were presented by age, gender and region and expressed per 100000 person-years or people with 95\% CIs. Ten year age-bands were selected for age stratification. Direct standardisation by age and gender used the 2012 population as a reference. The trend with time and region was analysed using Poisson regression adjusting for age and gender with an interaction term. A subsequent analysis of prevalence over time also adjusted for length of data contribution.

Using only individuals from HES-linked practices, the SLE incidence and prevalence in different ethnic groups were estimated.

Data management and analysis were performed using StataMP4 software V.13 (Statacorp, Texas, USA). The significance level was 0.05 .

\section{RESULTS}

\section{Incidence}

A total of 8681127 people contributed 55839080 person-years of follow-up, of whom 2740 had a new diagnosis of SLE (incidence 4.91 per 100000 person-years; 95\% CI 4.73 to 5.09).

\section{Temporal trend}

Table 1 shows the trend in incidence by year. There was an annual $1.8 \%$ decline $(95 \%$ CI 0.8 to 2.7 , p for trend $<0.001$ ) with a peak incidence in the year 2000 (5.93/100 000 personyears (95\% CI 5.14 to 6.83)) and a minimum in the year 2010 (4.00/100 000 person-years (95\% CI 3.45 to 4.64)). For comparison, when using a minimum of 3 years of registration, the annual incidence declined by $1.9 \%$ (95\% CI 0.9 to 2.9 , p for trend $<0.001)$ with a peak of $5.34 / 100000$ person-years $(95 \%$ CI 4.60 to 6.20$)$ in 2000 and a minimum of $3.51 / 100000$ person-years (95\% CI 3.00 to 4.12 ) in 2010 .

\section{Age and gender}

The incidence in females was 5.8 times that of males $(8.34 /$ 100000 person-years (95\% CI 8.01 to 8.69 ) vs $1.44 / 100000$ person-years (95\% CI 1.30 to 1.58$), \mathrm{p}<0.001)$. The mean age at diagnosis was 48.9 years (SD 16.9). Women were significantly younger than men at diagnosis (48.3 years (SD 16.8) vs 52.1 years (SD 17.2), $\mathrm{p}<0.001)$. The peak age of incidence for women (40-49 years) was earlier than that for men (6069 years) (figure 1A). The incidence was greater in females compared with males for all ages.

\section{Region}

There was geographic variation in incidence, with the lowest in the West Midlands (3.87/100 000 person-years (95\% CI 3.31 to 4.43)) and the highest in the East of England (6.03/100 000 person-years (95\% CI 5.36 to 6.69)) (figure 2A). There was no obvious trend with latitude, but the overall effect of region was statistically significant $(\mathrm{p}<0.001)$.

\section{Ethnicity}

Of the 8681127 participants, 5408624 were attending HES-linked practices, including 1643 incident cases (60\%). Table 2 illustrates the variation in SLE incidence by ethnicity. People of Black Caribbean ethnicity had the highest incidence (31.46/100 000 person-years (95\% CI 22.48 to 44.03$)$ ). In comparison, the incidence in White people was 6.73/100 000 person-years (95\% CI 6.35 to 7.14 ). The effect of ethnic group on incidence was statistically significant $(\mathrm{p}<0.001)$.

\section{Alternative definitions}

Using the fully comprehensive definition, the incidence was $6.23 / 100000$ person-years (95\% CI 6.03 to 6.44). In cases with 
Table 1 SLE incidence rate (IR) and prevalence by year, 1999-2012

\begin{tabular}{|c|c|c|c|c|c|c|c|}
\hline Year & $\begin{array}{l}\text { Number of } \\
\text { incident } \\
\text { cases }\end{array}$ & Person-years & $\begin{array}{l}\text { Crude IR, per } \\
100000 \text { person-years } \\
(95 \% \mathrm{Cl})\end{array}$ & $\begin{array}{l}\text { Standardised } I^{*}, \text { per } \\
100000 \text { person-years } \\
(95 \% \mathrm{Cl})\end{array}$ & $\begin{array}{l}\text { Number of } \\
\text { prevalent } \\
\text { cases }\end{array}$ & $\begin{array}{l}\text { Crude point prevalence, } \\
\text { per } 100000(95 \% \mathrm{CI})\end{array}$ & $\begin{array}{l}\text { Standardised point } \\
\text { prevalence*, per } 100000 \\
\text { person-years }(95 \% \mathrm{CI})\end{array}$ \\
\hline 1999 & 138 & 2708850 & 5.09 (4.31 to 6.02$)$ & 5.10 (4.25 to 5.96$)$ & 1875 & 64.63 (61.74 to 67.62 ) & 64.99 (62.04 to 67.93$)$ \\
\hline 2000 & 191 & 3221486 & 5.93 (5.15 to 6.83$)$ & 5.87 (5.03 to 6.71$)$ & 2312 & 66.67 (63.98 to 69.44$)$ & 66.60 (63.87 to 69.33$)$ \\
\hline 2001 & 189 & 3558271 & 5.31 (4.61 to 6.13 ) & 5.30 (4.54 to 6.06$)$ & 2674 & 69.78 (67.16 to 72.47$)$ & 69.97 (67.30 to 72.63$)$ \\
\hline 2002 & 226 & 3850272 & 5.87 (5.15 to 6.69$)$ & 5.82 (5.06 to 6.59$)$ & 3062 & 73.21 (70.64 to 75.85$)$ & 73.77 (71.15 to 76.38$)$ \\
\hline 2003 & 209 & 4010316 & 5.21 (4.55 to 5.97 ) & 5.19 (4.49 to 5.90$)$ & 3319 & 76.24 (73.67 to 78.88$)$ & 76.99 (74.36 to 79.61$)$ \\
\hline 2004 & 182 & 4166948 & 4.34 (3.75 to 5.02$)$ & 4.34 (3.71 to 4.98$)$ & 3528 & 78.00 (75.45 to 80.62$)$ & 78.04 (75.46 to 80.62$)$ \\
\hline 2005 & 236 & 4285893 & 5.53 (4.87 to 6.28$)$ & 5.54 (4.84 to 6.25$)$ & 3775 & 81.23 (78.66 to 83.86$)$ & 81.26 (78.66 to 83.86$)$ \\
\hline 2006 & 179 & 4326228 & 4.14 (3.57 to 4.79$)$ & 4.13 (3.53 to 4.74 ) & 3902 & 83.65 (81.05 to 86.32$)$ & 84.39 (81.74 to 87.05$)$ \\
\hline 2007 & 213 & 4365260 & 4.88 (4.27 to 5.58$)$ & 4.85 (4.20 to 5.51$)$ & 4076 & 86.31 (83.68 to 89.00 ) & 87.18 (84.49 to 89.86$)$ \\
\hline 2008 & 213 & 4369525 & 4.87 (4.26 to 5.58$)$ & 4.87 (4.22 to 5.53$)$ & 4190 & 88.62 (85.96 to 91.35 ) & 88.61 (85.93 to 91.29 ) \\
\hline 2009 & 195 & 4385184 & 4.42 (3.84 to 5.09$)$ & 4.42 (3.80 to 5.05$)$ & 4316 & 91.16 (88.46 to 93.92 ) & 91.17 (88.46 to 93.89$)$ \\
\hline 2010 & 173 & 4324739 & 4.02 (3.47 to 4.67 ) & 4.03 (3.43 to 4.63 ) & 4382 & 93.45 (90.70 to 96.26$)$ & 94.61 (91.80 to 97.43$)$ \\
\hline 2011 & 209 & 4239545 & 4.93 (4.30 to 5.65$)$ & 4.92 (4.26 to 5.59$)$ & 4429 & 95.81 (93.01 to 98.67 ) & 96.67 (93.81 to 99.53$)$ \\
\hline 2012 & 187 & 4026564 & 4.64 (4.02 to 5.36$)$ & 4.64 (3.98 to 5.31$)$ & 4413 & 97.04 (94.19 to 99.94$)$ & 97.04 (94.18 to 99.90$)$ \\
\hline
\end{tabular}

supporting evidence, the incidence was $4.58 / 100000$ personyears $(95 \%$ CI 4.40 to 4.76$)$. The trends in age, gender, region, year and ethnicity were similar between definitions (see online supplementary table S2).

\section{Prevalence}

During the study period, there were 7732 eligible prevalent cases with SLE of which 6634 were female (86\%).

\section{Temporal trend}

There was a linear 3.1\% increasing annual trend in prevalence from $64.63 / 100000$ in 1999 (95\% CI 61.74 to 67.62) to $97.04 / 100000$ in 2012 (95\% CI 94.19 to 99.94) (p for trend $<0.001$ ) (table 1). Adjusting for length of follow-up, in addition to age and gender there remained an increasing linear trend of $2.5 \%$ (95\% CI 2.3 to $2.8, \mathrm{p}<0.001)$.

\section{Age and gender}

In every year, females had a significantly higher prevalence of SLE than males. There was an increasing trend in both genders, which was more marked in females such that the ratio between genders increased from 5.07 (95\% CI 4.48 to 5.73) in 1999 to 6.75 (95\% CI 6.18 to 7.38 ) in 2012 (figure 3).

The overall peak age of prevalence was 60-69 years. The peak age in prevalence for men (80-89 years) was later than that of women (60-69 years) (figure $1 \mathrm{~B})$.

\section{Region}

In 1999, the North East had the lowest prevalence (45.88/ 100000 (95\% CI (30.21 to 61.56)) and Northern Ireland the highest (94.42/100 000 (95\% CI 73.39 to 115.44$)$ ), whereas in 2012 the East Midlands had the lowest prevalence (65.16/ 100000 (95\% CI 48.52 to 85.68)) and Northern Ireland remained the highest $(120.12 / 100000 \quad(95 \%$ CI 103.39 to 138.78)) (figure 2B).

\section{Ethnicity}

In all, 2812963 of the 4547778 denominator population in 2012 attended HES-linked practices (61.9\%) and were eligible for this analysis. Table 2 shows the variation in prevalence with ethnicity on 1 July 2012. Similar to incidence, people of Black
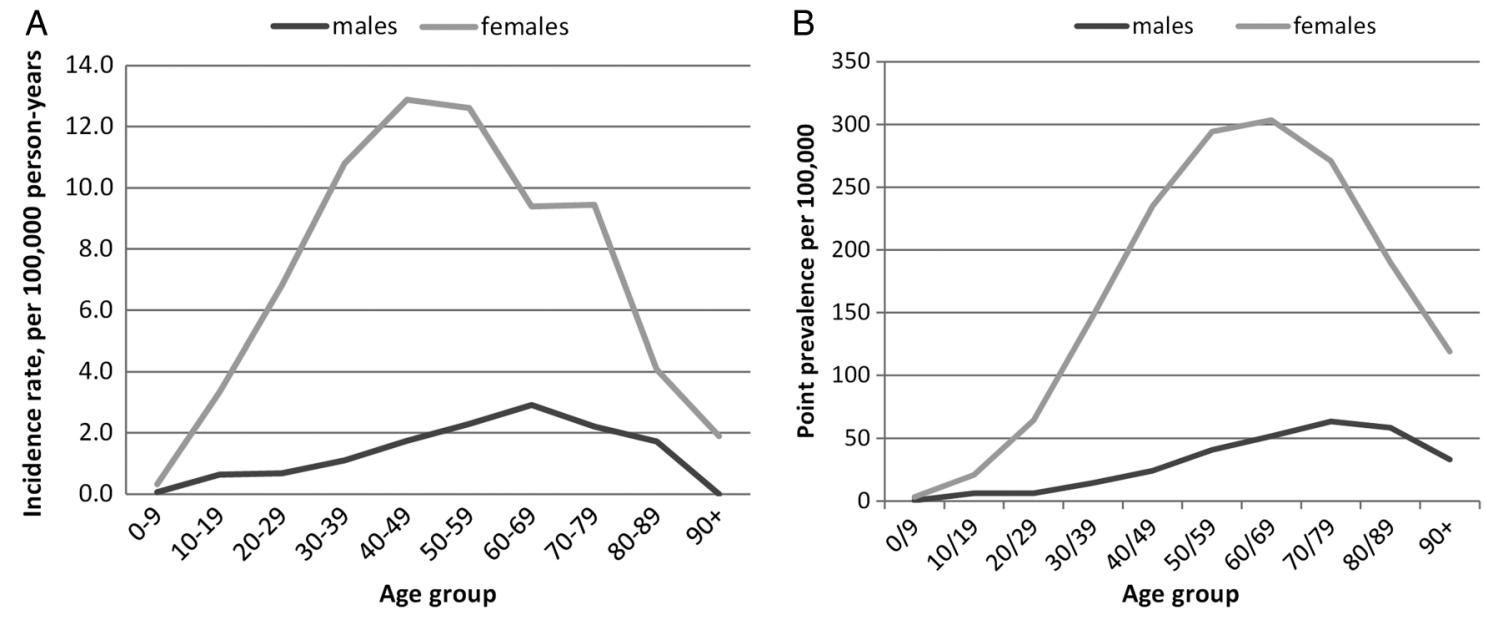

Figure 1 Line chart of age and gender-specific (A) incidence rate 1999-2012 and (B) point prevalence in 2012 for systemic lupus erythematosus. 
A

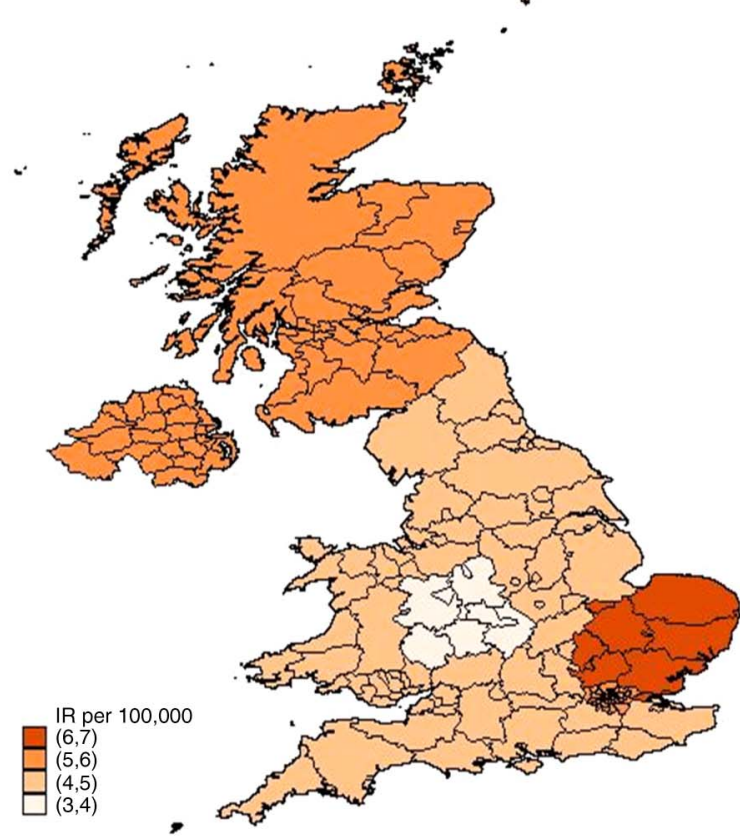

B

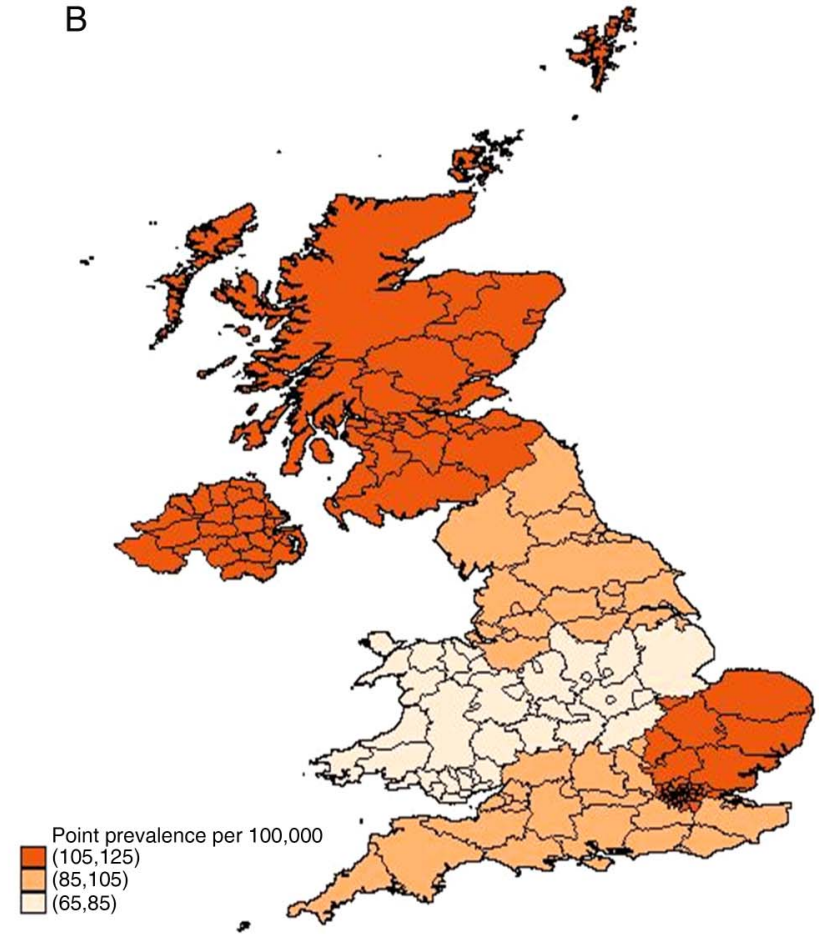

Figure 2 Choropleth map of age and gender standardised systemic lupus erythematosus (A) incidence rate (IR) 1999-2012 and (B) point prevalence in 2012.

Caribbean ethnicity had the highest prevalence $(517.51$ per 100000 people, $95 \%$ CI 398.54 to 660.84).

\section{Alternative definitions}

The prevalence of SLE in 2012 with the fully comprehensive definition was $125.51 / 100000(95 \%$ CI 122.26 to 128.76$)$ and in cases with supporting evidence was $88.09 / 100000$ (95\% CI 85.38 to 90.86 ). The trends for year, age, gender, region and ethnicity were similar to that of the first definition, with variation in the regional differences (see online supplementary table S2).

\section{DISCUSSION}

For people with our primary definition of SLE, the incidence for 1999-2012 was 4.91 per 100000 person-years (95\% CI 4.73 to 5.09) and the prevalence in 2012 was 97.04 per 100000 people (95\% CI 94.19 to 99.94). Our findings suggest that although the prevalence is increasing, the incidence is decreasing. We confirm the female predominance, which is approximately six times that of males. The peak age of incidence is 50-59 years. There is regional variation in incidence and prevalence of SLE with the highest incidence in the East of England and the highest prevalence in Northern Ireland. Black Caribbean is the ethnic group with the highest incidence and prevalence. Similar trends were found with all 3 definitions of SLE.

Our estimates of incidence and prevalence of SLE are higher than those of previous UK studies. ${ }^{1-5}{ }^{7-9}$ Although this could be due to increases with time, our incidence decreased with time. A more likely explanation is that our primary definition included subtypes of SLE such as lupus nephritis and cerebral lupus which may have been excluded from previous studies. For example, Hopkinson $e t a l^{1}$ invited cases for assessment, verified the diagnosis in person and required cases to meet the ACR criteria for SLE. This would have excluded minor cases, those with single organ disease and those unwilling to attend for assessment, which would have been included in our study. Our incidence estimate was similar to Somers $e t a l^{8}$ who used the CPRD during the period 1990-1999. However, they included cases with subacute cutaneous lupus. In contrast, Nightingale $e t \mathrm{al}^{7}$ had a significantly lower incidence of SLE despite including cases with discoid lupus as they required 3 years of registration before diagnosis plus supporting evidence within the medical record. Their estimate remained lower than our third definition which required supporting evidence (4.30/100 000 person-years (95\% CI 4.13 to 4.48$)$ ). The incidence found with our fully comprehensive definition of lupus $(6.23 / 100000$ person-years (95\% CI 6.03 to 6.44$)$ ) is much higher than previous UK studies of SLE and is the first study in the UK to include all cutaneous and systemic subtypes enabling an estimate of the full burden of lupus in the community. Interestingly, this estimate is still lower than some international studies of SLE incidence, for example from Taiwan, ${ }^{18}$ Argentina $^{19}$ and Brazil, ${ }^{20}$ demonstrating the variation between countries due to racial, genetic and environmental factors and also differences due to case definition and study methodology. With all 3 definitions, the estimated prevalence for SLE was above the European Union threshold for a 'rare disease'. ${ }^{21}$

The observed $50 \%$ increase in prevalence with time may be true as it occurred with all 3 definitions, for example, due to improved survival in people with SLE or due to ageing of the entire UK population. However, the latter is less likely as our estimates were age standardised. It may be due to more accurate recording within electronic records as paper notes have been replaced. Previous database studies have observed that the prevalence of chronic diseases appears to increase with time due to length of data contribution, including one SLE study with a $61 \%$ increase in prevalence from 1992 to $1998 .^{9}{ }^{22}$ However, after adjusting for length of data contribution, our prevalence still increased with time. The decrease in incidence may be true 
Table 2 SLE incidence rate (IR) 1999-2012 and point prevalence in 2012 by ethnic group in HES-linked practices

\begin{tabular}{|c|c|c|c|c|c|c|}
\hline Ethnicity & Incident cases & Person-years & $\begin{array}{l}\text { Crude IR, per } 100000 \\
\text { person-years }(95 \% \mathrm{CI})\end{array}$ & Prevalent cases & Denominator & $\begin{array}{l}\text { Point prevalence per } \\
100000(95 \% \mathrm{Cl})\end{array}$ \\
\hline Bangladeshi & 0 & 32671 & 0.00 & 4 & 4983 & 80.27 (21.87 to 205.53 ) \\
\hline Black African & 15 & 108883 & 13.78 (8.31 to 22.85$)$ & 35 & 19465 & 179.81 (125.24 to 250.07$)$ \\
\hline Black Caribbean & 34 & 108073 & 31.46 (22.48 to 44.03$)$ & 64 & 12367 & 517.51 (398.54 to 660.84$)$ \\
\hline Black other & 12 & 53923 & 22.25 (12.64 to 39.19$)$ & 29 & 8393 & 345.53 (231.40 to 496.23$)$ \\
\hline Chinese & 4 & 42785 & 9.35 (3.51 to 24.91$)$ & 10 & 5308 & 188.39 (90.34 to 346.46$)$ \\
\hline Indian & 19 & 191858 & $9.90(6.32$ to 15.53$)$ & 45 & 23305 & 193.09 (140.84 to 258.37 ) \\
\hline Mixed & 12 & 102833 & 11.67 (6.63 to 20.55 ) & 24 & 17372 & 138.15 (88.52 to 205.56$)$ \\
\hline Other Asian & 14 & 80227 & 17.45 (10.34 to 29.46$)$ & 23 & 12864 & 178.79 (113.34 to 268.28$)$ \\
\hline Other & 13 & 237185 & 5.48 (3.18 to 9.44$)$ & 40 & 27921 & 143.26 (102.35 to 195.08$)$ \\
\hline Pakistani & 11 & 110598 & 9.95 (5.51 to 17.96$)$ & 24 & 16808 & 142.79 (91.49 to 212.46$)$ \\
\hline Unknown & 229 & 4858127 & 4.71 (4.14 to 5.37$)$ & 346 & 387193 & 89.36 (80.19 to 99.29$)$ \\
\hline White & 1098 & 16303929 & 6.73 (6.35 to 7.14$)$ & 1700 & 1263646 & 134.53 (128.21 to 141.08$)$ \\
\hline Unclassified & 182 & 12141118 & $1.50(1.30$ to 1.73$)$ & 353 & 1013338 & 34.84 (31.30 to 38.67 ) \\
\hline
\end{tabular}

or due to the possibility that prevalent cases were coded as incident cases in the early years of the study period. However, increasing the minimum registration period to 3 years there remained a small but significant negative trend with time, suggesting this was a true decrease.

When examining differences with age and gender, our study confirmed the known female predominance for people diagnosed with SLE, which was observed with every definition of SLE. The mean age of diagnosis of 49 years and peak age of incidence of 50-59 years is later than that which is conventionally taught, but is consistent with previous UK and some international studies. $\begin{array}{llllll} & 7 & 8 & 23 & 24 & \text { Males had a statistically significant }\end{array}$ later peak age of diagnosis compared with females in accord with findings from previous studies worldwide. ${ }^{8}$ 24-27

Although there was no clear trend with latitude, there were statistically significant regional differences in both SLE incidence and prevalence. Regional variation has been noted previously by Somers et $a l^{8}$ who also found the West Midlands to have the lowest incidence and but in contrast to our study found Northern Ireland to have the highest incidence. Reasons for this regional variation are unclear but may be due to a combination of local environmental or genetic factors, variation in ethnic mix or socio-economic factors, differences in coding,

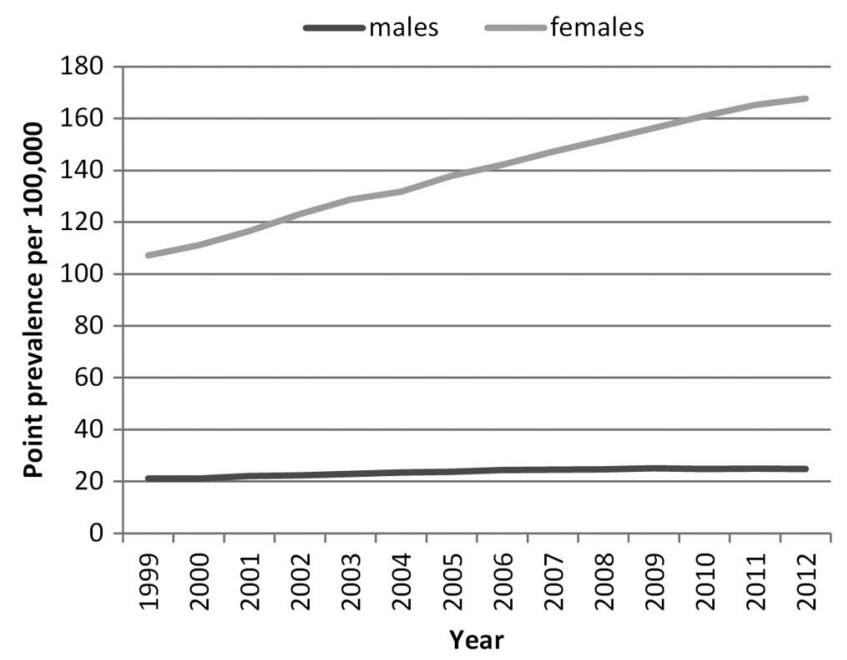

Figure 3 Annual systemic lupus erythematosus prevalence by gender. consultation, diagnosis or referral rates or differences in healthseeking behaviour between the populations.

Ethnicity is recognised to be an important factor in the development of SLE. This is the first study to report ethnic variation in SLE incidence and prevalence using the CPRD. We found that people of Black Caribbean origin had the highest incidence and prevalence of SLE. Combining ethnic groups, people of Asian descent had the second highest incidence and prevalence after Black people, and White people had the lowest incidence and prevalence of SLE. This supports findings from previous UK studies. 28

The main limitations of our study are those inherent in the use of a large database such as the CPRD. The date of diagnosis and accuracy of diagnosis could not be verified which may have led to missing data and misclassification bias. Unfortunately, we were unable to externally validate our cases. However, GPs would be unlikely to Read code a diagnosis of SLE without confirmation from secondary care (personal communication, GD) and previous studies of other chronic autoimmune diseases have shown good accuracy in recording on the CPRD with positive predictive values $>90 \% .^{16}{ }^{17}$ Ideally, every case should be assessed in person, but this is impractical due to the confidentiality of the database. Another limitation was that ethnicity data were only available for individuals attending English HES-linked practices and within these practices $50 \%$ of individuals had missing ethnicity data. This may have caused an overestimation of the ethnicspecific incidence and prevalence as people with ethnicity recorded are those admitted to hospital and hence more likely to have a chronic condition such as SLE. However, this should not affect the rate ratios between ethnic groups and therefore the trends remain valid. In addition, to maintain the sample size for the analysis of region, age and gender, ethnicity could not be adjusted for. This would be an interesting future study.

In summary, the incidence of SLE in the UK is decreasing and the prevalence increasing. This increase in prevalence suggests that SLE is no longer a 'rare' disease, which has implications for healthcare planning. These data confirm the known predilection for SLE in women. The peak age of diagnosis is in middle age, contrary to the generally held belief that lupus mainly targets young people. There is UK-wide variation. Black Caribbean is the ethnic group with the highest incidence and prevalence. Future research on geographic variation and ethnicity is warranted. 
Acknowledgements We would like to thank Lupus UK for funding this project.

Contributors All authors contributed to the conception, study design,

interpretation of the data, and to the drafting and approval of the final manuscript. FR performed the analysis.

Funding Lupus UK.

Competing interests None.

Ethics approval Independent Scientific Advisory Committee (ISAC) for MHRA Database Research (Protocol 13_092).

Provenance and peer review Not commissioned; externally peer reviewed.

Open Access This is an Open Access article distributed in accordance with the Creative Commons Attribution Non Commercial (CC BY-NC 4.0) license, which permits others to distribute, remix, adapt, build upon this work non-commercially, and license their derivative works on different terms, provided the original work is properly cited and the use is non-commercial. See: http://creativecommons.org/ licenses/by-nc/4.0/

\section{REFERENCES}

1 Hopkinson ND, Doherty M, Powell RJ. The prevalence and incidence of systemic lupus erythematosus in Nottingham, UK, 1989-1990. Br J Rheumatol 1993;32:110-15.

2 Johnson AE, Gordon C, Palmer RG, et al. The prevalence and incidence of systemic lupus erythematosus in Birmingham, England. Relationship to ethnicity and country of birth. Arthritis Rheum 1995:38:551-8.

3 Samanta A, Roy S, Feehally J, et al. The prevalence of diagnosed systemic lupus erythematosus in whites and Indian Asian immigrants in Leicester city, UK. Br J Rheumatol 1992:31:679-82.

4 Gourley IS, Patterson CC, Bell AL. The prevalence of systemic lupus erythematosus in Northern Ireland. Lupus 1997;6:399-403.

5 Hochberg MC. Prevalence of systemic lupus erythematosus in England and Wales, 1981-2. Ann Rheum Dis 1987:46:664-66.

6 Tan EM, Cohen AS, Fries JF, et al. The 1982 revised criteria for the classification of systemic lupus erythematosus. Arthritis Rheum 1982;25:1271-7.

7 Nightingale AL, Farmer RD, de Vries CS. Incidence of clinically diagnosed systemic lupus erythematosus 1992-1998 using the UK General Practice Research Database. Pharmacoepidemiol Drug Saf 2006;15:656-61.

8 Somers EC, Thomas SL, Smeeth L, et al. Incidence of systemic lupus erythematosus in the United Kingdom, 1990-1999. Arthritis Rheum 2007:57:612-18.

9 Nightingale AL, Farmer RD, de Vries CS. Systemic lupus erythematosus prevalence in the UK: methodological issues when using the General Practice Research Database to estimate frequency of chronic relapsing-remitting disease. Pharmacoepidemiol Drug Saf 2007:16:144-51.

10 de Vries C, Nightingale A, Farmer R. Epidemiology of systemic lupus erythematosus in the United Kingdom: comment on the article by Somers et al. Arthritis Rheum 2008;59:297; author reply 97-8.

11 Voss A, Green A, Junker P. Systemic lupus erythematosus in Denmark: clinical and epidemiological characterization of a county-based cohort. Scand I Rheumatol 1998;27:98-105
12 Alamanos $Y$, Voulgari PV, Siozos C, et al. Epidemiology of systemic lupus erythematosus in northwest Greece 1982-2001. J Rheumatol 2003:30:731-5.

13 Leonhardt T. Family studies in Systemic Lupus. Erythematosus Acta Med Scand 1964;176 (Suppl 416):1-156

14 Walley T, Mantgani A. The UK General Practice Research Database. Lancet 1997;350:1097-9.

15 Lewis JD, Bilker WB, Weinstein RB, et al. The relationship between time since registration and measured incidence rates in the General Practice Research Database. Pharmacoepidemiol Drug Saf 2005;14: 443-51.

16 Watts RA, Al-Taiar A, Scott DGI, et al. Prevalence and incidence of Wegener's granulomatosis in the UK general practice research database. Arthritis Care Res (Hoboken) 2009;61:1412-16.

17 Marieke Schoonen W, Kucera G, Coalson J, et al. Epidemiology of immune thrombocytopenic purpura in the General Practice Research Database. $\mathrm{Br} J$ Haematol 2009:145:235-44.

$18 \mathrm{Yu} \mathrm{KH}$, See LC, Kuo CF, et al. Prevalence and incidence in patients with autoimmune rheumatic diseases: a nationwide population-based study in Taiwan. Arthritis Care Res (Hoboken) 2013;65:244-50.

19 Scolnik M, Marin J, Valeiras SM, et al. Incidence and prevalence of lupus in Buenos Aires, Argentina: a 11-year health management organisation-based study. Lupus Sci Med 2014;1:e000021.

20 Pereira Vilar MJ, Sato El. Estimating the incidence of systemic lupus erythematosus in a tropical region (Natal, Brazil). Lupus 2002;11:528-32.

21 The European Parliament and The Council of the European Union. Decision No 1295/1999/EC of 29 April 1999: adopting a programme of Community action on rare diseases within the framework for action in the field of public health (1999 to 2003). Off J Eur Commun 1999;L155/1.

22 Kuo $C F$, Grainge MJ, Mallen C, et al. Rising burden of gout in the UK but continuing suboptimal management: a nationwide population study. Ann Rheum Dis 2015:74:661-7.

23 Jonsson $\mathrm{H}$, Nived $\mathrm{O}$, Sturfelt $\mathrm{G}$, et al. Estimating the incidence of systemic lupus erythematosus in a defined population using multiple sources of retrieval. $\mathrm{Br} J$ Rheumatol 1990;29:185-8.

24 Bernatsky S, Joseph L, Pineau CA, et al. A population-based assessment of systemic lupus erythematosus incidence and prevalence-results and implications of using administrative data for epidemiological studies. Rheumatology (Oxford) 2007:46:1814-18.

25 Lerang K, Gilboe I, Garen T, et al. High incidence and prevalence of systemic lupus erythematosus in Norway. Lupus 2012;21:1362-9.

26 Lopez P, Mozo L, Gutierrez C, et al. Epidemiology of systemic lupus erythematosus in a northern Spanish population: gender and age influence on immunological features. Lupus 2003;12:860-5.

27 Chiu YM, Lai CH. Nationwide population-based epidemiologic study of systemic lupus erythematosus in Taiwan. Lupus 2010;19:1250-5.

28 Hopkinson ND, Doherty M, Powell RJ. Clinical features and race-specific incidence/ prevalence rates of systemic lupus erythematosus in a geographically complete cohort of patients. Ann Rheum Dis 1994;53:675-80. 